\title{
Inkonsistensi Putusan Mahkamah Agung dalam Membatalkan Putusan Arbitrase
}

\author{
Yeni Widowaty, Fadia Fitriyanti
}

DATA NASKAH

Masuk: 5 Oktober 2016

Diterima: 16 November 2016

Terbit: 8 Desember 2016

KORESPONDEN PENULIS:

Fakultas Hukum Universitas

Muhammadiyah Yogyakarta

Jl. Lingkar Selatan, Taman Tirto

Kasihan, Yogyakarta

E-mail:

yenni_widowatie@yahoo.com yantifadia@yahoo.com

\section{ABSTRACT}

This research has 3 aims, the first is to examines the consideration of the Supreme Court in deciding the cancellation of arbitration decision under Article 70 and beyond Article 70 of Arbitration Act, the second is to review and analyze theories used in the consideration of the Supreme Court to cancel the Arbitration Decision. The third is to formulate concept in deciding the cancellation of Arbitration based on the principle of justice. This type of research is normative judicial research.Approach used in this research is case study approach. In more detail of the data obtained, processed and analyzed and presented in descriptive qualitative. The result of the research is divided into several parts, the first shows that according to the consideration of Deision of Supreme Court No.729/K/Pdt.Sus/2008 see Article 70 of the Arbitrase Act is limitative, different with Supreme Court Decision No.03/Arb/ BTU of 2005 interpeting Article is enunciatif.The second, the Great Judge who cancel the arbitrase decision according to Article 70 Arbitration Act which is limitative by using Analytical theory.the Great Judge cancel the arbitrase decision refers to reasons beyond Article 70 of Rbitrase Act using Progressive Law theory. The third, according to procedural fairness the reason for cancellation is based on decision Article No.70 Arbitrase Act is too limitative comparing to Article 34 of the UNICITRAL Model Law.This substantive justice should be limited to the signs, so that arbitrators use it arbitrarily.

Keywords: Inconsistency, Supreme Court Decision, Cancellation, Arbitrase Decision

\section{ABSTRAK}

Penelitian ini pertama mengkajipertimbangan Mahkamah Agung(MA) dalam memutuskan pembatalan putusan Arbitrase baik menurut alasan pembatalan berdasarkan Pasal 70 dan diluar Pasal 70 Undang-Undang Tentang 
Arbitrase, kedua mengkaji dan menganalisis teori yang digunakan MA dalam pertimbangan untuk membatalkan Putusan Arbitrase. Ketiga merumuskan suatu konsep dalam memutuskan pembatalan Putusan Arbitrase yang berbasis kepada asas keadilan. Jenis penelitian yang digunakan adalah penelitian yuridis normatif.Beberapa pendekatan yang digunakan dalam melakukan analisis dalam penelitian ini ialah pendekatan kasus.Secara lebih rinci data yang diperoleh dari penelitian, diolah dan dianalisis disajikan secara deskriptif kualitatif.Hasil penelitian menunjukkan pertama berdasarkan pertimbangan Putusan MARI No. 729/K/Pdt.Sus/2008 melihat Pasal 70 UU Arbitrase bersifat limitatif, Berbeda dengan Putusan MARI No.03/Arb.BTU 2005 yang menafsirkan Pasal 70 bersifat enunciatif.Kedua Hakim Agung yang membatalkan putusan arbitrase berdasarkan Pasal 70 UU Arbitrase yang bersifat limitatif menggunakan teori Analitis.Hakim Agung yang membatalkan putusan arbitrase mengacu pada alasan diluar Pasal 70 UU Arbitrase menggunakan teori hukum Progresif.Ketiga Berdasarkan keadilan Prosedural alasan pembatalan berdasarkan ketentuan Pasal 70 UU Arbitrase terlalu limitatif jika dibandingkan dengan Pasal 34 The UNICITRAL Model Law. Keadilan substantif ini harus dibatasi dengan rambu-rambu, agar arbiter menggunakannya tidak semena-mena.

Kata kunci: Inkonsistensi, Putusan Mahkamah Agung, Pembatalan, Putusan Arbitrase

\section{PENDAHULUAN}

\section{a. Latar Belakang}

Dalam dunia bisnis, tentunya banyak pertimbangan yang mendasari para pelaku bisnis untuk memilih arbitrase sebagai upaya penyelesaian perselisihan yang akan atau mereka hadapi (Sudiarto dan Zaeni Asyhadie, 2004:32).Ada berbagai alasan yang dapat digunakan para pelaku bisnis untuk memilih arbitrase sebagai upaya untuk menyelesaikan sengketa dagangnya antara lain dapat dibaca dalam Alinea ke empat Penjelasan Umum Undang-Undang Nomor 30 Tahun 1999 tentang Arbitrase dan Alternatif Penyelesaian Sengketa selanjutnya disebut UU Arbitrase.

Pada umumnya lembaga arbitrase mempunyai kelebihan dibandingkan dengan lembaga peradilan. Kelebihan tersebut antara lain:

1. Dijamin kerahasiaan sengketa para pihak;
2. Dapat dihindari kelambatan yang diakibatkan karena hal procedural dan administratif;

3. Para pihak dapat memilih arbiter yang menurut keyakinannya mempunyai pengetahuan, pengalaman serta latar belakang yang cukup mengenai masalah yang disengketakan, jujur dan adil;

4. Para pihak dapat menentukan pilihan hukum untuk menyelesaikan masalahnya serta proses dan tempat penyelenggaraan arbitrase dan;

5. Putusan arbiter merupakan putusan yang mengikat para pihak dan dengan melalui tata cara (prosedur) sederhana saja ataupun langsung dapat dilaksanakan.

Salah satu kelebihan penyelesaian melalui arbitrase dibandingkan dengan pengadilan dapat dihindari kelambatan yang diakibatkan karena hal procedural dan administrative. Ini sesuai dengan salah satu asas yang berlaku dalam Hukum Arbitrase yaitu Asas Final and Binding yaitu suatu putusan arbitrase bersifat putusan akhir dan langsung mengikat para pihak. Putusan arbitrase tidak dapat dilanjutkan dengan upaya hukum lain, seperti banding atau kasasi. Asas ini pada prinsipnya memang sudah disepakati oleh para pihak dalam klausula atau perjanjian arbitrase mereka. Tapi dalam UU Arbitrase diberi upaya hukum bagi para pihak yaitu pembatalan putusan arbitrase apabila memenuhi syarat-syarat yang tercantum dalam Pasal 70 UU Arbitrase

UU Arbitrase mengatur tentang pembatalan putusan Arbitrase dalam Pasal 70 yang menyatakan bahwa para pihak dapat mengajukan permohonan pembatalan apabila putusan arbitrase tersebut diduga mengandung unsur-unsur pemalsuan surat atau dokumen, atau ditemukan dokumen yang disembunyikan oleh pihak lawan, atau putusan diambil dari hasil tipu muslihat yang dilakukan oleh salah satu pihak dalam pemeriksaan sengketa. Namun demikian dalam praktek pembatalan putusan arbitrase berdasarkan Pasal 70 tersebut oleh Pengadilan Negeri hingga Mahkamah Agung diputuskan secara inkonsistensi.Pada satu sisi Mahkamah Agung membatalkan putusan Arbitrase hanya dapat dilakukan berdasarkan alasan-alasan yang terdapat dalam Pasal 70 yaitu putusan Mahkamah Agung Nomor 727/K/ Pdt.Sus/2008.Dalam hal ini Pasal 70 diartikan limitatif, pada sisi lain Mahkamah Agung menyatakan pembatalan putusan arbitrase dapat dilaksanakan berdasarkan alasan diluar Pasal 
70 yaitu Putusan Mahkamah Agung Nomor 03/Arb/Btl/ 2005. Tentunya Putusan Mahkamah Agung menimbulkan ketidakadilan dan ketidakpastian hukum bagi para pihak yang bersengketa.

\section{b. Rumusan Masalah}

Berdasarkan pendahuluan di atas, maka masalah-masalah penelitian yang dikaji adalah sebagai berikut:

1. Bagaimanakah pertimbangan Mahkamah Agung dalam memutuskan pembatalan putusan arbitrase baik menurut alasan pembatalan berdasarkan Pasal 70 dan diluar Pasal 70 UU Nomor 30 Tahun 1999 tentang Arbitrase dan Alternatif Penyelesaian Sengketa?

2. Teori apakah yang digunakan oleh Mahkamah Agung dalam memutuskan pembatalan arbitrase tersebut?

3. Bagaimana merumuskan suatu konsep pembatalan putusan arbitrase yang berbasiskan keadilan?

\section{c. Tujuan}

Tujuan khusus yang akan dicapai dalam penelitian ini adalah:

1. Mengkaji mengenai pertimbangan Mahkamah Agung dalam memutuskan pembatalan putusan Arbitrase baik menurut alasan pembatalan berdasarkan Pasal 70 dan diluar Pasal 70 UU Arbitrase,

2. Mengkaji dan menganalisis teori yang digunakan Mahkamah Agung dalam pertimbangan untuk membatalkan Putusan Arbitrase.

3. Merumuskan suatu konsep dalam memutuskan pembatalan Putusan Arbitrase yang berbasis kepada asas keadilan

\section{METODE PENELITIAN}

Penelitian ini merupakan penelitian yuridis normatif. Jenis data yang dipergunakan dalam penelitian ini adalah data sekunder yang terdiri dari bahan hukum primer, bahan hukum sekunder dan tersier. Pendekatan yang digunakan dalam ialah pendekatan undang-undang, pendekatan perbandingan dan pendekatan kasus (case approach) (Peter Mahmud Marzuki,:93-95).Untuk memperkuat data sekunder dilakukan wawancara pada narasumber Hakim Pengadilan
Negeri Jakarta Pusat Tafsir Sembiring, SH. Metode analisis yang digunakan adalah priskriptif-analitis, yaitu dengan cara pemaparan dan analisis tentang isi (struktur) hukum yang berlaku, sistematisasi gejala hukum yang dipaparkan dan dianalisis, interpretasi dan penilaian hukum yang berlaku. (D.H.M. Meuwissen, 1994: 26-28). Selanjutnya menganalisis mengenai pertimbangan Mahkamah Agung dalam memutuskan pembatalan putusan arbitrase baik menurut alasan pembatalan berdasarkan Pasal 70 dan diluar Pasal 70 UU Nomor 30 Tahun 1999 tentang Arbitrase dan Alternatif Penyelesaian Sengketa.

\section{HASIL PENELITIAN DAN ANALISIS}

\section{Pertimbangan Mahkamah Agung dalam}

Memutuskan Pembatalan Putusan Arbitrase

baik Menurut Pasal 70 UU Arbitrase atau

\section{Diluar Pasal 70 UU Arbitrase}

Inkosistensi Putusan Mahkamah Agung mengenai pembatalan putusan arbitrase mengacu kepada Pasal 70 UU Arbitrase menimbulkan dua aliran: pertama Mahkamah Agung yang konsisten dengan bunyi Pasal 70 menyatakan bahwa alasan pembatalan putusan arbitrase haruslah mengacu kepada isi Pasal 70 dan Pasal 70 UU Arbitrase bersifat limitative.

Menjadi yurisprudensi dalam Putusan MARI No.729/KI Pdt.Sus/2008, sehingga pembatalan putusan arbitrase yang tidak mengacu kepada Pasal 70 tidak dapat dibenarkan. Aliran yang kedua dimana Mahkamah Agung menyatakan Pasal 70 tidak bersifat limitatif dan telah diakui dan menjadi yurisprudensi dalam Putusan MARI No.03/Arb.BTU 2005 tanggal 17 Mei 2005 menyatakan kata "antara lain" dalam Penjelasan Umum UU Arbitrase tersebut memungkinkan Pemohon untuk mengajukan permohonan pembatalan putusan arbitrase atas alasan diluar yang tertera dalam Pasal $70 \cup \cup$ Arbitrase.

Adapun Pertimbangan Putusan MARI No.729/K/Pdt.Sus/ 2008 adalah

1. Judex Facti yang membatalkan putusan BANI a quo tanpa memenuhi syarat-syarat yang diatur dalam Pasal 70 Undang-Undang No. 30 Tahun 1999 telah salah menerapkan hukum sebab alasan pembatalan putusan 
Arbitrase sebagaimana diatur dalam Pasal 70 UndangUndang No. 30 Tahun 1999 tentang Arbitrase dan Alternatif Penyelesaian Sengketa tersebut telah dirinci secara limitatif sebagai berikut:

a. surat atau dokumen yang diajukan dalam pemeriksaan, setelah putusan dijatuhkan diakui palsu atau dinyatakan palsu;

b. setelah putusan diambil ditemukan dokumen yang bersifat menentukan yang sengaja disembunyikan pihak lawan; atau

c. putusan diambil dari hasil tipu muslihat yang dilakukan oleh salah satu pihak dalam pemeriksaan sengketa;

Amar putusan Mahkamah AgungNo.729/K/Pdt.Sus/ 2008:

a. Mengabulkan permohonan banding dari Pemohon banding PT. PADJADJARAN INDAH PRIMA tersebut;

b. Membatalkan putusan Pengadilan Negeri Sumedang No.10/Pdt.G/ 2008/PN.Smd. tanggal 12 Juni 2008 MENGADILI SENDIRI:

a. Menguatkan putusan BANI No. 03/2007/BANI/Bandung tanggal 17 Maret 2008 baik dalam Konvensi maupun dalam Rekonvensi;

b. Menghukum Termohon banding/Pemohon untuk membayar biaya perkara dalam semua tingkat peradilan, yang dalam tingkat banding ini ditetapkan sebesar Rp.500.000,- (lima ratus ribu rupiah);

Pertimbangan Putusan MARI No.03/Arb.BTU 2005 tanggal 17 Mei 2005 adalah

1. Dasar permohonan pembatalan putusan arbitrase yang diajukan oleh Pemohon adalah bahwa BANI Perwakilan Surabaya tidak memiliki kewenangan untuk memeriksa dan memutus sengketa antara Pemohon dengan Termohon, dimana Termohon adalah Pemohon Arbitrase dalam perkara Nomor: 15/ARB/BANI JATIM/III/2004 karena dalam perjanjian antara Pemohon dan Termohon yang menjadi dasar sengketa (Appointment of General Sales Agent (Passengers) tanggal 29 Oktober 2001 dan Appointment of General Sales Agent (Cargo) tanggal 5 Nopember 2002) tidak terdapat klausul arbitrase yang secara tegas memberikan kewenangan kepada BANI perwakilan Surabaya untuk memeriksa dan memutus sengketa antara Pemohon dan Termohon;

2. Untuk itu Pemohon telah menyurati BANI Surabaya beberapa kali,namun BANI Surabaya tetap memeriksa dan memutus sengketa antara Pemohon dengan Termohon tersebut;

3. Mengenai alasan permohonan pembatalan putusan arbitrase yang diajukan oleh Pemohon/Termohon Arbitrase ke Pengadilan Negeri; bahwa dalam penjelasan umum Undang-Undang Nomor 30 Tahun 1999 tertera bahwa "Bab VII mengatur tentang pembatalan putusan arbitrase. Hal ini dimungkinkan karena beberapa hal, antara lain:

a. surat atau dokumen yang diajukan dalam pemeriksaan, setelah putusan dijatuhkan, diakui palsu atau dinyatakan palsu;

b. setelah putusan diambil ditemukan dokumen yang bersifat menentukan, yang disembunyikan pihak lawan; atau

c. putusan diambil dari hasil tipu muslihat yang dilakukan oleh salah satu pihak dalam pemeriksaan sengketa";

Bahwa kata "antara lain" tersebut memungkinkan Pemohon untuk mengajukan permohonan pembatalan putusan arbitrase atas alasan diluar yang tertera dalam Pasal 70 Undang-Undang Nomor 30 Tahun 1999, seperti halnya dengan alasan kompetensi absolut yang dikemukakan oleh Pemohon

4.Mahkamah Agung akan mempertimbangkan mengenai ada atau tidaknya klausula arbitrase dalam kedua perjanjian yang dibuat oleh Pemohon dan Termohon (bukti P1 = T1 dan bukti P2 = T2); bahwa baik Pasal 24 dalam bukti P1 (Appointment of General SalesAgent (Passengers) tanggal 29 Oktober 2001) maupun Pasal 23 bukti P2 (Appointment of General Sales Agent (Cargo) tanggal 5 Nopember 2002) berbunyi:"ArbitrationThis Agreement shall in all respects be interpreted in accordance withthe Laws of the Republic of Yemen"; bahwa dari rumusan tersebut jelas terlihat bahwa penyelesaian sengketa yang timbul berdasarkan perjanjian-perjanjian itu harus diselesaikan menurut hukum Republik Yaman, dan karenanya BANI Perwakilan 
Surabaya tidak berwenang untuk menyelesaikan sengketa antara Pemohon dengan Termohon;

Amar putusan Mahkamah Agung No.03/Arb.BTU 2005:

1 Menolak permohonan banding dari Pemohon Banding: PT.COMARINDO EXPRES TAMA TOUR \& TRAVEL tersebut;

2 Memperbaiki amar putusan Pengadilan Negeri Jakarta Selatan Nomor: 254/Pdt.P/2004/PN.Jak.Sel. tanggal 6 Januari 2005 sebagaimana yang dipertimbangkan di atas sehingga selengkapnya berbunyi sebagai berikut;

DALAM EKSEPSI: Menolak eksepsi Termohon:

\section{DALAM POKOK PERKARA}

a. Mengabulkan permohonan Pemohon;

b. Membatalkan putusan arbitrase dari BANI Perwakilan Surabaya Nomor 15/ARB/BANIJATIM/III/2004 tanggal 19 Agustus 2004

c. Menyatakan BANI Perwakilan Surabaya tidak berwenang untuk memeriksa dan memutus sengketa antara Pemohon dan Termohon yang didasarkan pada Appointment of General Sales Agent (Passengers) tanggal 24 Oktober 2001 dan Appointment of General Sales Agent (Cargo) tanggal 5 Nopember 2002

d. Menghukum Pemohon Banding/Termohon untuk membayar biaya perkara dalam kedua tingkat peradilan, yang dalam tingkat banding ini ditetapkan sebesar Rp 500.000,- (lima ratus ribu rupiah);

Majelis hakim dalam Putusan MARI No. 729/K/Pdt.Sus/ 2008 melihat Pasal 70 UU Arbitrase bersifat limitative, Berbeda dengan Putusan MARI No.03/Arb.BTU 2005 yang menafsirkan Pasal 70 bersifat enunciatif, mendasari pada kata "antara lain" dalam Penjelasan Umum UU Arbitrase memberi celah menambah alasan lain diluar pasal 70 UU Arbitrase, selain itu juga alasan pembatalan yang diatur dalam Pasal 70 belum memuat hal-hal yang bersifat fundamental. Menurut Hikmahanto Juwana dasar permohonan pembatalan putusan arbitrase tidaklah limitatif berdasarkan Pasal 70 UU Arbitrase, ada beberapa alasan pembatalan putusan arbitrase yaitu keterlambatan dalam memutus perkara dimana waktu yang ditentukan dalam UU Arbitrase adalah 180 hari, ketiadaan perjanjian arbitrase, kewenangan dari prosedur pengambilan putusan arbitrase misalnya proses pemilihan arbiter, pemberlakuan hukum yang dipilih oleh para pihak dalam sengketa (Rengganis, 2011:75). Senada dengan pendapat Hikmahanto, menurut Priyatna Abdurrasyid (mantan Ketua BANI dan arbiter) terdapat alasan lain untukmembatalkan Putusan BANI di luar Pasal 70 Undang-Undangan Arbitrase, yaitu apabila terdapat "kesalahan prosedural" dalam putusan arbitrase. (Priyatna Abdurrasyid, 16). Meskipun dalam praktik arbitrase modern, pembatasan alasan pembatalan putusan arbitrase oleh undang-undang telah diakui sebagai prinsip yang universal paling tidak alasan pembatalan putusan arbitrase memuat hal-hal yang bersifat fundamental mengacu kepada Pasal 34 The UNICITRAL Model Law

\section{Teori yang Digunakan Mahkamah Agung} dalam Pertimbangan untuk Membatalkan

\section{Putusan Arbitrase}

Teori hukum memegang peranan penting dalam membimbing hakim menyusun putusan yang berkualitas dan mampu mengakomodir tujuan hukum, yaitu keadilan, kepastian, dan kemanfaatan hukum. Hakim Agung yang membatalkan putusan arbitrase berdasarkan Pasal 70 UU Arbitrase yang bersifat limitative menggunakan teori Analitis. Teori ini memandang penerapan hukum oleh hakim diimplementasikan secara mekanis.Hukum dipandang memiliki aturan yang lengkap dan terhimpun secara sistematis logis dalam kitab-kitab hukum kodifikasi. Menurut teori ini hakim dalam menerapkan hukum hanya mencocokkan kasus yang diadili dengan bunyi dari teks perundang-undangan. (M. Natsir Asnawi, 2014: 52). Hakim Agung yang membatalkan putusan arbitrase mengacu pada alasan diluar Pasal 70 UU Arbitrase menggunakan teori hukum Progresif.Pencetus teori hukum progresif adalah Satjipto Rahardjo. Konsep hukum progresif mirip dengan interessenjurisprude yang berangkat dari keraguan akan kesempurnaan logika yuridis dalam merespon kebutuhan atau kepentingan sosial dimasyarakat. Hakim tidak boleh lagi hanya berkutat dalam ruang gerak teks sempit dan tidak mampu menangkap kehendak dan kebutuhan sosial dan hukum yang ada. M. Natsir Asnawi, 2014: 69). Mengingat Putusan Hakim memiliki kekebalan hukum luar biasa hal ini 


\section{MEDIA
HUKUM}

didukung oleh aturan dan asas hukum. Dalam hal ini Mahkamah Agung telah mengeluarkan Surat Edaran Nomor 9 Tahun 1976 tentang Gugatan Terhadap Pengadilan dan Hakim yang menyatakan bahwa Hakim bebas dari gugatan ganti rugi atas kesalahan dalam perbuatan yang merupakan tugasnya dalam bidang peradilan dan meminta kepada seluruh pengadilan untuk dapat menolak gugatan tersebut. Ketentuan ini juga didukung dalam Surat Edaran Mahkamah Agung Nomor 4 Tahun 2002 mengenai apabila ada hakim yang dilaporkan ke polisi berkaitan dengan pelaksanaan tugasnya, maka MA menganjurkan kepada hakim atau pejabat pengadilan untuk tidak memenuhi panggilan tersebut. Disamping itu ada asas hukum Res judicata pro veritate habetur yang populer dimana putusan hakim harus dianggap benar. Bahkan menurut Sudikno Mertokusumo putusan hakim harus dianggap benar meskipun yang diajukan saksinya palsu dan hakim memutuskan perkara tersebut berdasarkan kesaksian palsu itu. Padahal putusan hakim diputuskan berdasarkan kesaksian palsu tapi harus dianggap benar, sampai memperoleh kekuatan hukum yang tetap atau diputuskan lain oleh pengadilan yang lebih tinggi (banding atau kasasi). Ini semua adalah untuk mencapai ketertiban masyarakat dan kepastian hukum yang merupakan harapan dan cita-cita masyarakat.(Sudikno Mertokusumo,2004: 8). Dengan demikian Putusan MARI No. 729/K/Pdt.Sus/2008 melihat Pasal 70 UU Arbitrase bersifat limitative dan Putusan MARI No.03/Arb.BTU 2005 yang menafsirkan Pasal 70 bersifat enunciatif.Kedua putusan harus dianggap benar walaupun menimbulkan inkonsistensi dan ketidakpastian bagi masyarakat pencari keadilan.Apabila dianalisa lebih jauh terjadinya inkonsistensi ini karena adanya perbedaan pendekatan yang dilakukan oleh hakim Mahkamah Agung dalam menafsirkan Pasal 70 UU Arbitrase.

Menurut M.Natsir Asnawi Hakim dalam memutuskan suatu perkara dapat dikategorikan ke dalam perbedaan paradigma dimana hakim dikelompokkan menjadi dua yaitu menganut paradigm positivistik dan paradigm diluar positivistik.Tipologi hakim positivistik memposisikan dirinya sebagai corong undang-undang sehingga mengabdi sepenuhnya pada teks undang-undang. Hakim dalam hal ini menitikberatkan pada keadilan prosedural dengan titik tekan kepastian hukum.Sedangkan hakim tipologi diluar positivistik memposisikan dirinya sebagai creator bagi terciptanya keadilan substantive. Hakim bukan menjadi corong undangundang tetapi pembuat hukum.

\section{Konsep dalam Memutuskan Pembatalan}

\section{Putusan Arbitrase yang Berbasis kepada Asas}

\section{Keadilan}

Dalam diskursus konsep keadilan (justice) banyak ditemukan berbagai pengertian keadilan, diantaranya keadilan adalah menempatkan sesuatu pada tempatnya (proporsional), keadilan adalah keseimbangan antara hak dan kewajiban dan lain sebagainya. Demikian juga klasifikasi keadilan juga banyak ditemukan misalnya Aristoteles membagi keadilan komutatif dan distributif. Dalam konteks putusan hakim peradilan dalam hal ini putusan arbitrase yang sering disinggung adalah berupa keadilan prosedural (procedural justice) dan keadilan substantive (substantive justice). Keadilan prosedural adalah keadilan yang didasarkan pada ketentuan-ketentuan yang dirumuskan dari peraturan hukum formal, seperti mengenai tenggat waktu maupun syarat-syarat beracara di pengadilan lainnya. Sedangkan keadilan substantive adalah keadilan yang didasarkan pada nilai-nilai yang lahir dari sumber-sumber hukum yang responsive sesuai hati nurani.

Dengan demikian konsep keadilan dalam putusan dalam lembaga peradilan adalah sesuatu yang sangat dekat dengan pemenuhan hak dan kepentingan manusia, hanya saja tidak mudah diterapkan dalam praktek. Bisa saja terjadi putusan hakim dijatuhkan akan dirasakan berbeda oleh kedua belah pihak, yaitu satu pihak merasa adil jika keinginannya dikabulkan, tetapi pihak yang lain merasa putusannya tidak adil karena keinginannya tidak dapat terpenuhi. Sehingga hakeketnya persoalan keadilan itu implementasinya dalam praktek dirasakan adil atau tidak adil adalah berdasarkan penilaian masing-masing pihak, yang sangat mungkin berbeda. (Bambang Sutiyoso, 2010: 9).

Dalam tataran ideal untuk mewujudkan putusan hakim yang memenuhi harapan pencari keadilan, yang mencerminkan nilai-nilai hukum dan rasa keadilan masyarakat, ada beberapa unsure yang harus dipenuhi dengan baik. Gustav Radbruch mengemukakan idealnya dalam suatu putusan 
harus memuat idée des recht, yang meliputi 3 unsur yaitu keadilan (gerechtigkeit), kepastian hukum (rechtsicherheit), keadilan (zwechtmassigkeit).Ketiga unsur tersebut seharusnya dipertimbangkan secara proporsional sehingga dapat menghasilkan putusan yang berkualitan memenuhi harapan para pencari keadilan. (Sudikno Mertokusumo, 2004:15).

Pola penegakan hukum dipengaruhi oleh tingkat perkembangan masyarakat, tempat hukum tersebut berlaku atau diberlakukan.Dalam masyarakat sederhana, pola penegakan hukumnya dilaksanakan melalui prosedur dan mekanisme yang sederhana pula. Namun dalam masyarakat modern yang bersifat rasional dan memiliki tingkat spesialisasi dan diferensiasi yang begitu tinggi, pengorganisasian penegakan hukumnya menjadi begitu kompleks dan sangat birokratis.Sehingga yang memegang peranan penting dalam proses penegakan hukum bukan hanya manusia yang menjadi aparat penegak hukum namun juga organisasi yang mengatur dan mengelola operasionalisasi proses penegakan hukum. Dalam proses perubahan sosial, faktor-faktor yang berpengaruh terhadap bekerjanya hukum dalam masyarakat bukan hanya faktor internal dalam sistem hukum itu sendiri (hukum, aparat, organisasi dan fasilitas) tapi juga faktorfaktor eksternal diluar sistem hukum, seperti sistem sosial, politik, ekonomi, budaya bahkan dalam era globalisasi sekarang ini, pengaruh faktor tata pergaulan internasional pun tidak dapat diabaikan.

Perkembangan institusi arbitrase internasional beberapa waktu belakangan ini berjalan sangat cepat dan dinamis, serta telah diterima dengan baik oleh komunitas perdagangan internasional sebagai suatu institusi yang dapat digunakan dalam menyelesaikan pelbagai sengketa bisnis. Negara tetangga kita seperti Malaysia (Kuala Lumpur Regional Centre), Singapura (Pusat Arbitrase Internasional Singapura), Australia (Pusat Arbitrase Internasional Australia) telah menunjukkan keseriusan dalam mengembangkan arbitrase internasional sehingga ketiga Negara tersebut merupakan salah satu wilayah paling dinamis untuk kegiatan arbitrase internasional. Sayang sekali keterlibatan Indonesia tidak terlalu menonjol karena di Indonesia sendiri tidak ada lembaga arbitrase yang dinyatakan sebagai lembaga arbitrase internasional, kendatipun BANI dapat menyelesaikan perkara- perkara yang bersifat internasional.(Sudikno Mertokusumo, 2004: 147).

Dalam kaitannya dengan pembatalan putusan arbitrase jika mengacu kepada keadilan substantive dan keadilan procedural. Mengacu kepada keadilan procedural pembatalan putusan arbitrase harusnya di Indonesia mengacu kepada Model Law pada Arbitrase Dagang Internasional yang diadopsi oleh United Nations Commission on International Trade and Law pada tanggal 21 Juni 1985 (the UNICITRAL Model Law) dan ditulis oleh UU Arbitrase dari banyak negara di dunia. Prosedur-prosedur yang universal ini merupakan alasan utama untuk mendasarkan pada pandangan bahwa putusan arbitrase adalah putusan yang dapat diterima, patut, adil untuk menyelesaikan sengketa domestik dan melintasi batas negara. Dengan demikian alasan pembatalan berdasarkan ketentuan Pasal 70 UU Arbitrase terlalu limitatif jika dibandingkan dengan Pasal 34 The UNICITRAL Model Law yaitu para pihak atau salah satu pihak yang membuat perjanjian arbitrase merupakan orang yang tidak mempunyai kapasitas atau kewenangan (underincapacity) untuk membuat suatu perjanjian, sehingga mengakibatkan perjanjian arbitrase itu menjadi tidak sah, padahal perjanjian arbitrase menjadi dasar perkara itu diselesaikan melalui arbitrase, harus dipenuhi asas audi alteram partem yaitu para pihak diberi kesempatan yang sama untuk cukup membela kepentingannya masing-masing misalnya apabila salah satu pihak tidak diberitahu secara wajar tentang penunjukan arbiter, atau untuk melakukan pembelaan, putusan arbitrase dianggap tidak wajar karena majelis arbiter telah bersikap parsial atau berat sebelah sehingga proses pemeriksaan perkara berlangsung secara tidak jujur, majelis arbitrase telah menjatuhkan putusan yang melampaui kewenangannya, susunan majelis arbitrase tidak sesuai dengan perjanjian yang disepakati oleh para pihak, kecuali perjanjian itu bertentangan dengan ketentuan uu yang tidak dapat dikesampingkan, perkara yang diselesaikan tidak dapat diselesaikan dengan hukum dinegara itu,putusan bertentangan dengan ketertiban umum Negara itu. Dengan demikian UU Arbitrase harus diubah menyesuaikan Pasal 34 The UNICITRAL Model Law agar juga memuat hal-hal yang membatalkan secara fundamental yang memuat keadilan masyarakat baik nasional maupun internasional. 


\section{MEDIA
HUKUM}

Keadilan substantif merupakan sesuatu yang abstrak. Konsep keadilan itu akan diperoleh melalui kemampuan dan keahlian arbiter dalam menjelaskan fakta-fakta yang ditemukan dalam perkara dan juga prinsip-prinsip dan komponen-komponen yang bersifat universal yang merupakan pedoman bagi arbiter untuk menjatuhkan putusan. Berdasarkan wawancara dengan Hakim Pengadilan Negeri Jakarta Pusat Tafsir Sembiring (wawancara 30 Agustus 2016), keadilan substantive ini harus dibatasi dengan ramburambu, agar hakim menggunakannya tidak semena-mena kecuali dengan alasan tidak mengacu kepada UU dalam memutuskan perkara karena alasan bertentangan dengan ketertiban umum. Dengan demikian kebebasan hakim itu tidak mutlak tetaplah dibatasi baik secara mikro maupun makro.Secara mikro kebebasan hakim dibatasi dengan Pancasila, UUD 1945, peraturan perundang-undangan, kehendak para pihak, ketertiban umum, dan kesusilaan.Secara makro kebebasan hakim dibatasi oleh sistem pemerintahan, sistem politik, sistem ekonomi dan sebagainya. Sebagai contoh peradilan masa Orde lama yang kita jumpai dalam Pasal 23 UU Nomor 13 Tahun 1965 tentang Pengadilan dalam Lingkungan Peradilan Umum dan Mahkamah Agung, yang memungkinkan Presiden campur dan turun tangan dalam persidangan peradilan. Disini sistem pemerintahanlah yang membatasi kebebasan hakim. (Bambang Sutiyoso dan Sri Hastuti Puspitasari, 2005: 51 52).

Menurut Philippe Fouchard, dalam praktik arbitrase modern, pembatasan alasan pembatalan putusan arbitrase oleh undang-undang telah diakui sebagai prinsip yang universal, dan menurut Sujayadi alasan pembatalan putusan arbitrase hanya dapat dilakukan untuk alasan-alasan yang bersifat fundamental yang diatur dalam UU (Ilhami Ginang Pratidina,2014: 314) dan harusnya merupakan suatu hal dimana pengadilan tidak perlu ikut campur dalam sengketa dimana para pihak telah sepakat menyelesaikannya melalui arbitrase apalagi pembatalan putusan arbitrase (less intervention of state).

\section{SIMPULAN DAN SARAN}

\section{a. Simpulan}

Berdasarkan rumusan masalah, hasil penelitian, dan pembahasan yang disajikan sebelumnya dapat ditarik kesimpulan sebagai berikut:

1.Mencermati kedua pertimbangan putusan MARI No.729/ K/Pdt.Sus/2008 dan No.03/Arb. BTU 2005 jelas terlihat inkonsistensi alasan pembatalan putusan arbitrase. Majelis hakim dalam Putusan MARI No. 729/K/Pdt.Sus/2008 melihat Pasal 70 UU Arbitrase bersifat limitative, Berbeda dengan Putusan MARI No.03/Arb.BTU 2005 yang menafsirkan Pasal 70 bersifat enunciatif.

2. Hakim Agung yang membatalkan putusan arbitrase berdasarkan Pasal 70 UU Arbitrase yang bersifat limitative menggunakan teori Analitis. Menurut teori ini hakim dalam menerapkan hukum hanya mencocokkan kasus yang diadili dengan bunyi dari teks perundangundangan. Hakim Agung yang membatalkan putusan arbitrase mengacu pada alasan diluar Pasal 70 UU Arbitrase menggunakan teori hukum Progresif.Pencetus teori hukum progresif adalah Satjipto Rahardjo. Hakim tidak boleh lagi hanya berkutat dalam ruang gerak teks sempit dan tidak mampu menangkap kehendak dan kebutuhan sosial dan hukum yang ada

3.Mengacu kepada keadilan procedural, alasan pembatalan berdasarkan ketentuan Pasal 70 UU Arbitrase terlalu limitatif jika dibandingkan dengan Pasal 34 The UNICITRAL Model Law. Keadilan substantive ini harus dibatasi dengan rambu-rambu, agar arbiter menggunakannya tidak semena-mena kecuali dengan alasan tidak mengacu kepada UU dalam memutuskan perkara asalkan karena alasan bertentangan dengan ketertiban umum

\section{b. Saran}

Berdasarkan kesimpulan di atas, peneliti mengusulkan rekomendasi bagi pengembang pendidikan, peneliti lebih lanjut, dan pihak terkait sebagai berikut:

sebaiknya UU Arbitrase yang berkaitan dengan Pasal 70 mengenai pembatalan putusan arbitrase diubah menyesuaiakan dengan ketentuan Pasal 34 The UNICITRAL Model Law sehingga tidak lagi terjadi inkonsistensi putusan Mahkamah Agung dalam membatalkan putusan arbitrase.

\section{DAFTAR PUSTAKA}

Abdulkadir Muhammad, (2004), Hukum dan Penelitian 
Hukum, Citra Aditya Bakti, Bandung

Bambang Sutiyoso,2010, Reformasi Keadilan dan Penegakan Hukum di Indonesia, UII Press, Yogyakarta Bambang Sutiyoso dan Sri Hastuti Puspitasari, 2005, Aspek-Aspek Perkembangan Kekuasaan Kehakiman di Indonesia, UII Press, Yogyakarta.

D.H.M. Meuwissen, Ilmu Hukum (Penerjemah B. Arif Sidharta), Pro Justitia, Jurnal Unika Parahyangan, Tahun XII No. 4, Oktober 1994, hlm. 26-28 dalam M Akib, Politik Hukum Pengelolaan Lingkungan Hidup dalam Perspektif Otonomi Daerah, Disertasi Undip, Semarang, 2011.

Hikmahanto Juwana, (2011), Pembatalan Putusan Arbitrase Internasional oleh Pengadilan Nasional, Jurnal Hukum Bisnis, Vol 21, Oktober-November 2002,

Ilhami Ginang Pratidina,2014, Jurnal Yuridika: Volume 29 No 3, September-Desember 2014

Maqdir Ismail, (2007), Pengantar Praktek Arbitrase di In donesia, Malaysia, Singapura dan Australia, Fakultas Hukum Universitas Al Azhar Indonesia, Jakarta

Mattew B Miles dan A Michael Huberman,(1992), Analisis Data Kualitatif, UI Press, Jakarta

Philippe Fouchard, et.al., (1999), Faouchard, Gaillard, Goldman on International Commercial Arbitration,Dordrecht, The Netherlands: Kluwer Law International

M.Natsir Asnawi, (2014), Hermeneutika Putusan Hakim, UII Press, Yogyakarta

Rengganis, (2011), Tinjauan Yuridis Pembatalan Putusan Arbitrase Nasional Berdasarkan Pasal 70 UU Nomor 30 Tahun 1999 (Studi Kasus terhadap Beberapa Putusan Mahkamah Agung RI),

Sudikno Mertokusumo, 2004, Mengenal Hukum Suatu Pengantar, Liberty, Yogyakarta

Sudiarto dan Zaeni Asyhadie, (2004), Mengenal Arbitrase Salah Satu Alternatif Penyelesaian Sengketa Bisnis, PT Raja Grafindo Persada, Jakarta

Sujayadi, Patologi dalam Arbitrase Indonesia: Ketentuan Pembatalan Putusan Arbitrase dalam Pasal70 UU No. 30/199

Sutiyoso Bambang,(2010), Reformasi Keadilan dan Penegakan Hukum di Indonesia, UII Press, Yogyakarta 